\title{
NUMERICAL MODEL OF A HYBRID DAMPING SYSTEM COMPOSED OF A BUCKLING RESTRAINED BRACE WITH A MAGNETO RHEOLOGICAL DAMPER
}

\author{
Norin Filip-VACARESCU - PhD, Politehnica University of Timisoara, Department of Steel Structures and \\ Structural Mechanics, e-mail: norin.filip-vacarescu@upt.ro \\ Cristian VULCU - Lecturer,PhD, Politehnica University of Timisoara, Department of Steel Structures and \\ Structural Mechanics, e-mail: cristian.vulcu@upt.ro \\ Dan DUBINA - Professor, Member of the Romanian Academy, PhD, Politehnica University of Timisoara, \\ Department of Steel Structures and Structural Mechanics, Romanian Academy, Fundamental and Advanced \\ Technical Research Centre Timisoara, e-mail: dan.dubina@upt.ro
}

\begin{abstract}
This paper discusses the concept of a hybrid damper made from a combination of two dissipative devices. A passive hysteretic device like steel Buckling Restrained Brace (BRB) can be combined with a magneto-rheological (MR) Fluid Damper in order to obtain a hybrid dissipative system. This system can work either as a semi-active system, if the control unit is available, or as a passive system, tuned for working according to performance based seismic engineering (PBSE) scale of reference parameters (i.e. interstory drift).
\end{abstract}

Keywords: Damper, Hybrid, Seismic, Dissipative, Performance.

\section{Introduction}

Seismic design of structures is a continuously growing field in civil engineering. The interest and exponential growth of this field was and is fuelled by the effects of some important earthquakes in history. The extensive damage or collapse as a result of this earthquake activity led to an increase in seismic demands and, in the attempt to improve structural response capacity, implementation of enhanced technical solutions. In current practice there are three efficient strategies to reduce seismic risk.

- reduce seismic forces

- appropriate the structural response to seismic demand

- enhance structural damping.

Enhancing damping is made by the introduction of energy dissipation devices in the structural system which can absorb the seismic energy and can modify the period of vibration of the structure to more favorable values for global behavior. In general these devices can be of three types:

- seismic isolation devices

- passive energy dissipation devices

- active and semi-active energy dissipation devices.

Although damping devices such as buckling restrained braces (BRB), tuned mass dampers, magnetorheological (MR) and viscous (FV) dampers, or friction dampers (FD) are being used in numerous buildings and are implemented in design codes, as technology advances there is a continuous need for improvement. Research in the last years has started to inquire in the possibility to combine already established damping devices to create Hybrid Damping Systems (HDS). These hybrid systems are conceived to provide additional damping capacity in the structure and/or provide special advantages in the structural system such as recentering capabilities or even the replaceability of damaged components [1]. This can be achieved by the 
interaction between damping devices disposed in varied structural configurations. Together with the need of increased capacity and improved behavior of structure for major seismic events there has also been an increased interest in recent years to protect structures from dangerous vibrations that occur on a frequent basis, including here wind action and minor seismic events which are not covered by the action of high capacity dampers. Hybrid devices show great promise in answering both the demands of low and high level vibration in buildings in the framework of performance based design of structures. The purpose of this paper is to show the potential of a hybrid system made of BRB coupled with a magneto-rheological damper that can reduce the response of the structure to low and high levels of seismic action as well as wind/vibration control capabilities.

Different combinations of damping devices have been proposed to create hybrid energy dissipation devices that serve different purposes. To reduce residual deformations that are the result of earthquake motions and that have an undesirable effect on the functionality of the buildings Wenke and Eric [1] suggested the use of a new hybrid device. The hybrid device is made from two Shape Memory Alloy (SMA) wires coupled with a viscous damper in the configuration applied in the center of chevron bracing system as shown in Fig. 1a.

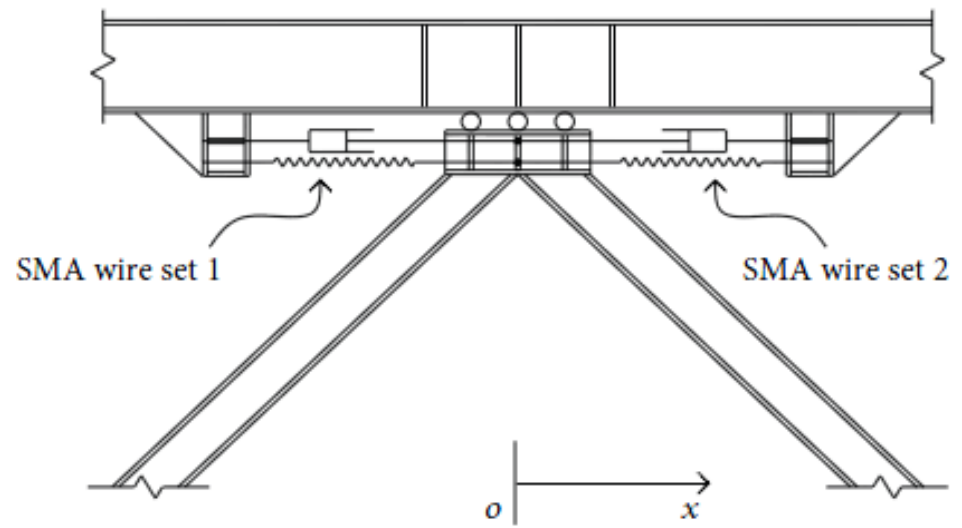

a.

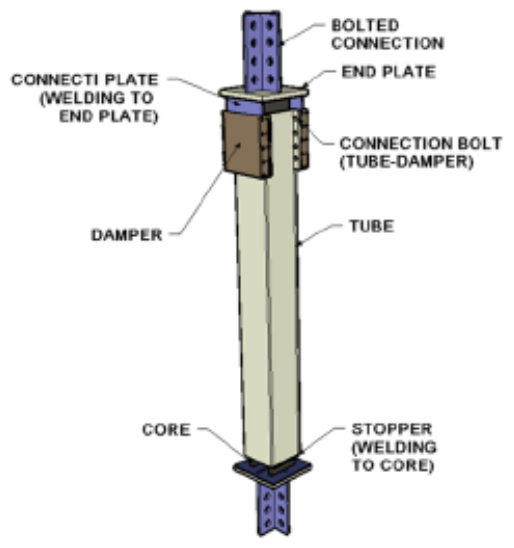

b.

Fig. 1 - a)Conceptual design of hybrid viscous SMA device [1];b) BRB with viscoelastic damper device[3]

Depending on the direction of motion of the chevron brace one of the SMA wires is active and will provide the recentering force. The viscous damper increases the overall damping of the structure and reduces story drift during the earthquake motion. Because it is a velocity dependant device, the visous damper has the advantage that after the seismic event it has no extra resistance allowing for the full recentering capacity of SMA wires to be used. This hybrid device could reduce both the peak and the residual story drift.

A great advantage of hybrid devices is that they have the capacity to answer to different levels of vibrations. As the modern performance based design approach is based on reduction of damage the damping devices that are added to the conventional structural systems are the active elements that dissipate the energy induced by the earthquake. This means that the structures remain in the elastic domain under earthquake action damage occurs only in the damping devices. Another concept of hybrid systems revolves around the combination between the passive damping devices installed with the structural systems they are installed on. For example Amadio et al. [2] suggested the use of a hybrid system made of partially restrained steel-concrete composite frames coupled with viscoelastic dissipative bracing. The system uses the increase of stiffness and dissipation capacity of the partial resistant composite frame together with the energy dissipation of the viscoelastic bracing leading to significant reduction of the displacement demand. Some examples can be found on the use of BRB's as part of a hybrid system, especially linked with viscoelastic dampers. Do-Hyun [3] suggested a BRB with a tube viscoelastic damper at one end (Fig. 1b). This hybrid system in conceived to dissipate the energy from low-level 
excitations (wind or minor earthquake) through the viscoelastic damper, while the BRB will act as the main energy dissipation device for higher levels of seismic action.

The study presented in the paper is part of a strategic grant POSDRU and will also be extended to an experimental testing program as part of on-going research program PN II nr. PCCA 77 / 2014Seismic Protection of Structures with Dissipative Braces Equiped with Nano-micro Magnetorheological Fluid Dampers („Protecția seismică a structurilor cu sisteme de contravântuiri disipative echipate cu amortizoare cu fluid nano-micro magneto-reologic (SEMNAL-MRD)"), a partnership led by Politehnica University Timisoara, that includes The Institute for Solid Mechanics of the Romanian Academy (IMSAR), Fundamental and Advanced Technical Research Centre of the Romanian Academy Timisoara, S.C.ROSEAL S.A and SC TEN SA.

\section{Hybrid system with friction damper}

The authors of the present paper conducted an experimental and numerical research to study the behaviour of an innovative friction damper[4]. The damper studied was a damper with a behaviour characterized by a starting zone with low stiffness, aimed at increasing the period of vibration of the structure, and subsequently reducing the seismic forces and a second zone with increased stiffness conceived to limit displacements for high values of seismic action which classifies it as a strain hardening friction damper (Fig. 2).

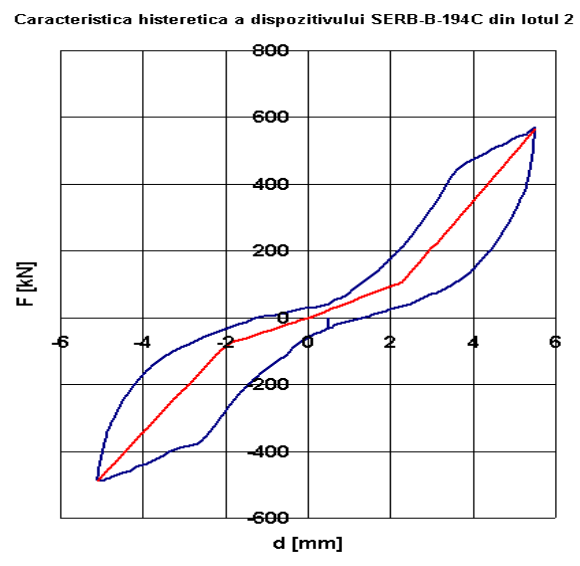

Fig. 2 - Hysteretic behaviour of SERB friction damper [5].

The research focused on the study of the seismic performance of chevron brace frame systems with friction dampers in the braces. Because of its distinct behaviour of this type of damper, it involved a different approach for the philosophy of design dissipative structures. The authors proposed a design concept which allowed the coupling of the friction damper and the conventional steel brace it was attached to, into a hybrid damping system that uses the best traits from both systems. This concept designed the damper with sufficient overstrength compared to the brace to assure that the brace has deformation in the plastic domain and is the weaker element in the configuration. This system should benefit from both the energy dissipation capacity of the brace and the supplemental damping from the device, and the failure will occur in the brace and not in the device creating this way hybrid damping system. This designed was linked to the performance base design approach so that for seismic motion levels corresponding immediate occupancy, the damper is the „active" element ensuring that the brace remains in elastic domain and providing an overall damping increase, while at levels corresponding to life safety the brace is the ,active" element according to the dissipative design concept. Experimental program was comprised by standalone tests on the friction dampers (Fig. 3a)and steel braces and in the second phase on the brace with damper assembly in a triangular configuration, hinged at both ends. (Fig. 3b). 


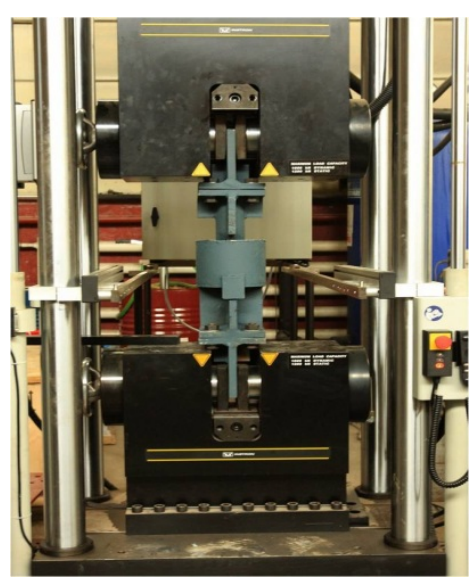

a.

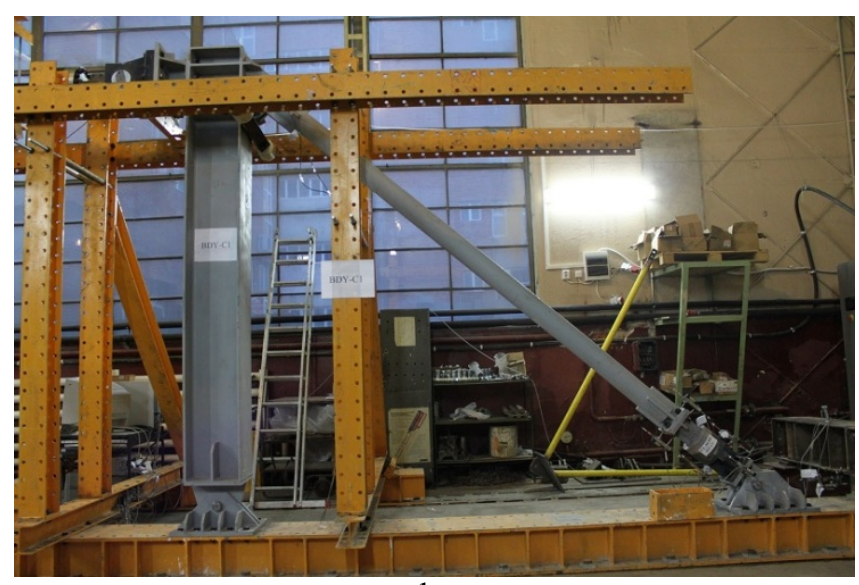

b.

Fig. 3 - a) Experimental test setup for single damper tests; b) Experimental brace with damper test setup[4].

The brace with damper hybrid system presented a behaviour that validated the design approach. Up to a level of two times the yield displacement (ey) the global behaviour is governed by the behaviour of the damper while at higher load levels it was governed entirely by the behaviour of the simple brace without damper, with energy dissipation by the formation of a plastic hinge in the brace. Failure in this design concept is represented by the failure of the brace in compression(Fig. 4).

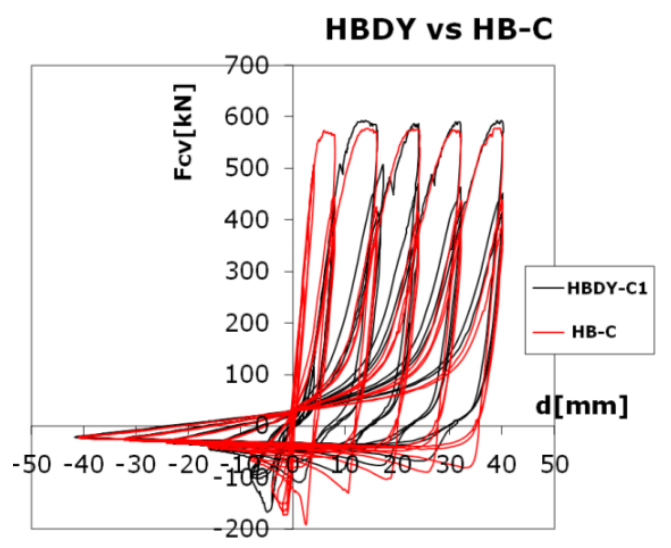

Fig. 4 - Experimental test results on brace with(HBDY-C1)/without(HB-C) [4].

Starting from the experimental data numerical models for damper and brace-damper assembly were validated. The buckling behaviour of brace was modelled using geometric imperfections and the damper model was constructed using a two link elements working in parallel, a bilinear symmetric behaviour type link combined with a gap-hook element that is employed to model the pinching of the curve. The coupled stiffness of these two elements in parallel yielded the desired stiffness for the device. These models were linked in series to provide the hybrid brace with damper system model which was implemented in a performance based analysis on the studied frames. Numerical time-history analysis were performed on concentrically braced frames using 7 seismic motions characteristic for stiff soil type with $\mathrm{T}_{\mathrm{C}}=0.5 \mathrm{~s}$, analysing the structure with and without dampers in the braces.

The conclusion was that this type of damper is efficient in reducing the seismic response of a building for earthquakes characterized by short corner period $\mathrm{T}_{\mathrm{C}}=0.5 \mathrm{~s}$ (stiff soil) by preventing the formation of plastic hinges at SLS and reducing the permanent displacement of the structure. However, for earthquakes characterized by long corner period $T_{C}=1.6 \mathrm{~s}$ (soft soil) this type of damper did not prove effective in improving the behaviour of the structure. This study showed the possibility to combine dissipative elements into forming a hybrid system that can be guided by design to act efficiently at different levels of seismic action (performance levels)[6]. 


\section{Hybrid system composed of a BRB brace and a magnetorheological damper}

\subsection{Magneto-rheological fluid dampers}

Because of the limitations of passive damping devices active damping devices were developed Active control systems are an evolution of passive devices that have sensors and real time control and evaluation systems that modify partially or completely the properties of the damping devices during the recorded ground motion in order to obtain an optimal behaviour of the structure. Because this type of damping devices is still largely dependent on a good power source a mixture between the two types was developed and so, semi-active type dampers like Magnetorheological Fluid Dampers (MRD) appeared, as an alternative to existing devices. These devices have properties that can be adjusted in real-time but cannot introduce mechanical energy in the structural system, acting like adjustable passive systems. Because semi-active devices have adaptive capabilities like the active systems but without the need of high power sources have made them very attractive for use in seismic resistant buildings. Many of these systems can even work on batteries which make them especially useful in the case of major earthquake events that can most likely interrupt power supply.

From constructive point of view semi-active dampers can be either mechanical or hydraulic dampers. The latter type allows the use of special fluids such as magnetic fluids to obtain certain damping characteristics. The MRD is an adjustable liquid damper that is able to overcome many of the shortcomings of other semi-active devices. MR liquids change their apparent viscosity when acted upon by a magnetic field. This transformation can occur in just millisecond which makes MR liquid dampers a highly controllable semi-active device. The MR dampers can work either as passive devices or as semi-active ones, having a variable hysteretic behaviour that can be controlled by the variation of the magnetic field in the device with the change of current intensity. The electromagnets installed act like control valves regulating the flow of liquid, by affecting the viscosity of the fluid over a certain area. MR dampers also have the advantage of being able to produce control forces at low velocities, having a high dynamic range. The behaviour of these dampers is characterised by large rectangular type hysteretic loops (Fig. 5).

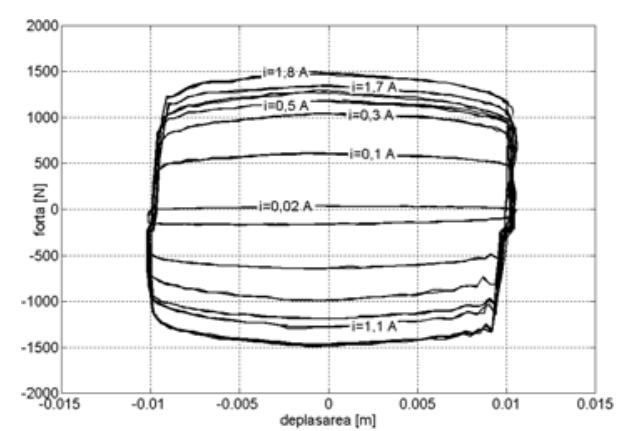

a.

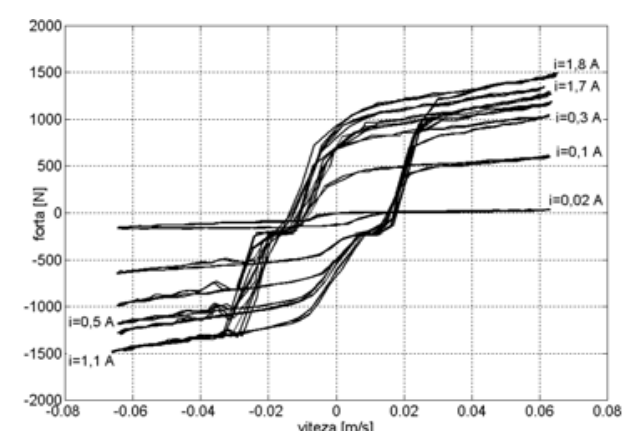

b.

Fig. 5 - a) Force-displacement and b)force-velocity results for sinusoidal input of $1 \mathrm{~Hz}$ [7].

The numerical modeling for the MR damper was made using Seismosoft SeismoStruct v7.0.2 [8] with the use of link element model. The model was calibrated on existing experimental results found in literature, more specifically results obtained by Sireteanu et al. [7] on a Lord RD1005-3 damper. For the purpose of this preliminary study the MR dampers were considered to work only as passive devices, having a constant behaviour under a given intensity of the electric current. For the preliminary study presented herein only the later was considered, taking as a reference point the behaviour of the friction damper under a constant intensity of the electric curent of $1.1 \mathrm{~A}$ and considering a frequency of excitation of $1 \mathrm{~Hz}$ under a constant sinusoidal loading history. After initial calibration the models were scaled to a higher capacity $F y=50 \mathrm{kN}$ to be used together with the BRB for the hybrid damping system. The dampers were also modelled with the 
use of link elements using a Ramberg-Osgood hysteresis behaviour set to a yield force of $\mathrm{Fy}=1400 \mathrm{~N}$, Ramberg-Osgood parameter $\gamma=10$ and yield displacement $\mathrm{dy}=1 \mathrm{~mm}$. This model has large hysteretic loops that are very close to the shape obtained for the MR dampers (Fig. 6) and is considered to be sufficiently accurate for the present study.

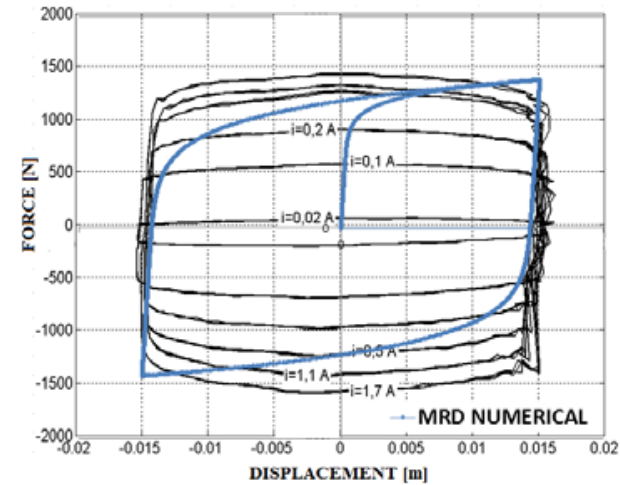

a.

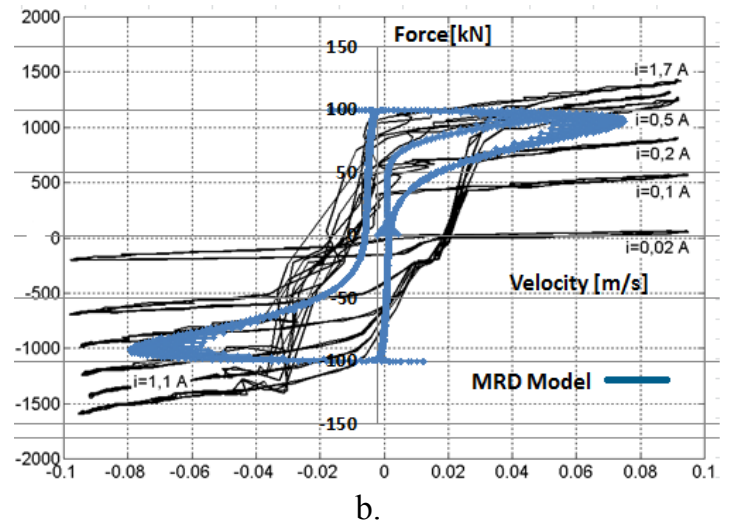

b.

Fig. 6 - Experimental behaviour [7] vs. numerical model of MRD.a)Force-dsplacement; b)Force-velocity

Because from technical point of view, MR dampers can still be considered limited in terms of capacity and can prove insufficient for high intensity seismic events, they are considered in the hybrid damping system proposed by this research as active component in reducing low level seismic excitation together with wind or vibration control.

\subsection{Buckling restrained braces}

Buckling restrained braces (BRB) are an energy dissipation system based on the limitation of local buckling of braces and was originally designed for seismic rehabilitation of structures but their use later extended to new structures. This type of braces appeared as a solution to low ductility of the classic bracing system by preventing local buckling in the compressed braces. As opposed to classic braces their behaviour is characterized by symmetric behaviour in tension and compression (Fig. 7b). The main concept of this system is to prevent the buckling of a ductile steel core that is introduced in a steel casing filled with concrete. Between the steel core and the concrete a slip surface is provided to ensure that axial loads are taken entirely by the steel core. This slip surface can be made from different materials, carefully selected to ensure a satisfactory slip between the steel and the concrete. The purpose of the concrete filling is to prevent the local buckling of the steel core and, together with the steel casing to prevent the global buckling of the brace resulting in a stable hysteretic behaviour ( Clark et al., 1999)[9](Fig. 7a). Buckling restrained braces are generally used in structural configuration as $\mathrm{V}$ and $\mathrm{X}$ braces, or diagonals.

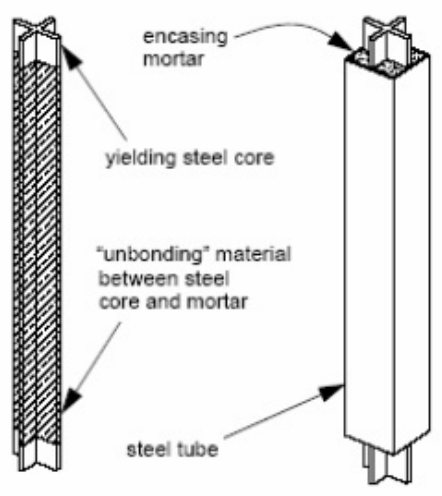

a.

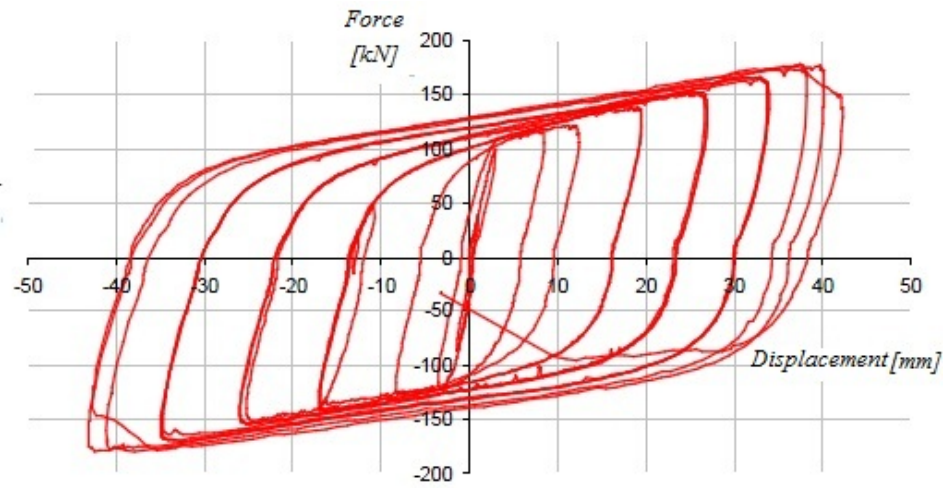

b.

Fig. 7 - a)BRB main components [9]; b) hysteretic behaviour [10]. 
The numerical model for the BRB was also made using a link type element in SeismoStruct. The model was calibrated on experimental research data from a grant developed in CEMSIG centre of Politechnica University Timisoara, in which several BRB's were conceived, manufactured and tested. Different interface materials between the steel core and the concrete fill were used for the experimental test braces which were tested under monotonic and cyclic test protocols by themselves and installed in a concrete frame. For the numerical model in the current study experimental data for the BRB with PVC transparent film interface material $(t=1 \mathrm{~mm})$ under ECCS [11] (European Convention for Constructional Steelworks) type load protocol was used. The protocol consists of a monotonic test to determine the force-displacement relationship of the specimen and to determine yield displacement $\mathrm{e}_{\mathrm{y}}$ and yield force $\mathrm{F}_{\mathrm{y}}$. With the determined values of $\mathrm{e}_{\mathrm{y}}$ the displacement based cyclic load protocol is constructed with one cycle at each elastic step of $0.25 \mathrm{ey}, 0.5 \mathrm{ey}, 0.75 \mathrm{ey}, 1 \mathrm{ey}$ and 3 cycles at each load step multiple of 2ey (2ey, 4ey, 6ey ,8ey, etc.). The other load protocol used in the tests was according to recomendations of AISC 2005 [12] (American Istitute of Steel Contruction) which characteristic of the loading protocol is the repetition of two cycles at $\mathrm{e}_{\mathrm{y}}$, followed by groups of two cycles with increments of $0.5 \mathrm{D}_{\mathrm{bm}}$, until the cumulative inelastic deformation reaches at least 200 times $e_{y}$. For the sake of simplicity a bilinear symmetric behaviour was again selected with parameters yield force $\mathrm{F}_{\mathrm{y}}=140 \mathrm{kN}$, hardening ratio $\mathrm{r}=0.04$ and stiffness of $\mathrm{K}_{0}=67000 \mathrm{~N} / \mathrm{mm}$.(Fig. $8 \mathrm{a}$ ). The two loading protocols are plotted in Figure 4.9 . The numerical model was considered to have a good balance of simplicity and accuracy compared to the behaviour obtained experimentally (Fig. 8b).

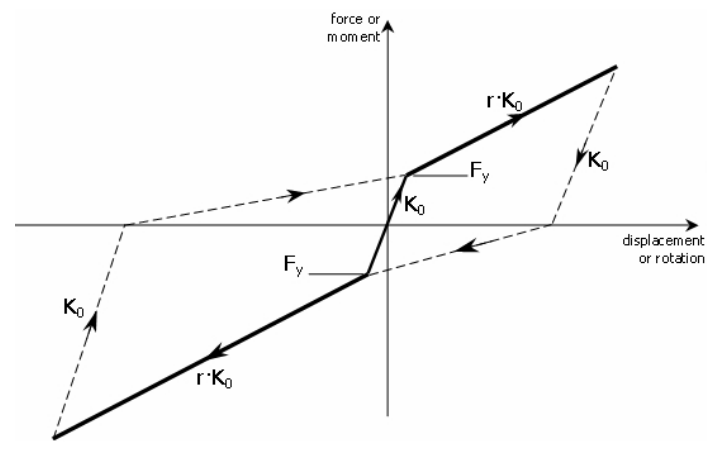

a.

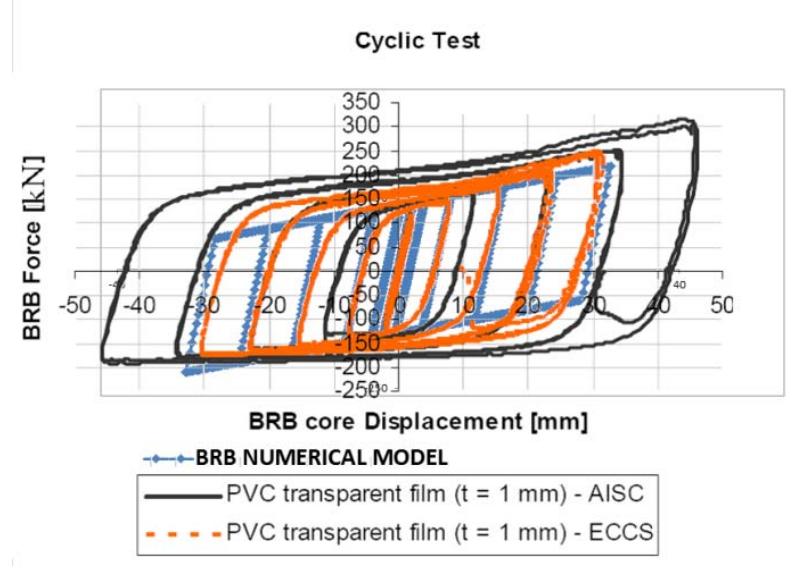

b.

Fig. 8 - a)Bilinear symmetric model;b) Hysteretic behaviour of BRB's: experimental vs. numerical [10].

The BRB's are meant to play their role in the hybrid system for medium to high levels of seismic action contributing with stiffness for reduction of story drift and high energy dissipation capacity due to their large symmetric hysteretic behaviour.

\subsection{Hybrid damping system}

The concept of hybrid damping system proposed in this study links in series two already established damping systems. Playing on their strengths these two elements, working together, can answer in an optimal way the demands of both low level and moderate to high level intensity of seismic motions. The model proposed here is a combination of a magneto-rheological fluid damper (MRD), working as a passive device, and a buckling restrained brace. The MRD has good damping characteristics at all levels of excitation and high adaptability of the behaviour making it adequate for use both as an adaptable passive device and as a semi-active one. The BRB is a well-known passive system used in many applications, with very high energy dissipation capacity due to its symmetric behaviour in tension and compression. The analytical 
models developed for the current study are simple numerical models used to study the multiphase behaviour concept of the hybrid system. The aim of this numerical study is to show that the hybrid system concept is a viable solution to fulfilling the demands of the structure at different performance levels and could be implemented in practice. From numerical model point of view the two elements will be connected in series and modelled as 2 link elements. After initial calibration the MR model was scaled to a higher capacity to be used together with the $\mathrm{BRB}$ for the hybrid damping system with $\mathrm{Fy}=50 \mathrm{kN}$, and Ramberg-Osgood parameter $\gamma=10$. The multi-phase behaviour of the hybrid damper is dependant also on another critical component which is the lock-out mechanism. This is a means that enables the system to pass from one stage to another, in this case from the MRD governed behaviour to the BRB. The lock-out mechanism should transfer enough force from the MR damper just before it has attained its ultimate damping capacity, to the BRB, which starts developing its own hysteretic behaviour from that point.

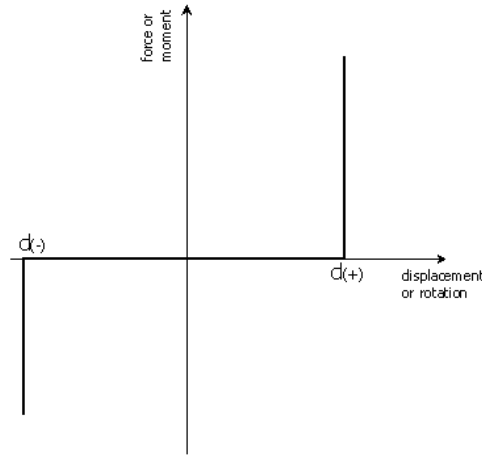

a.

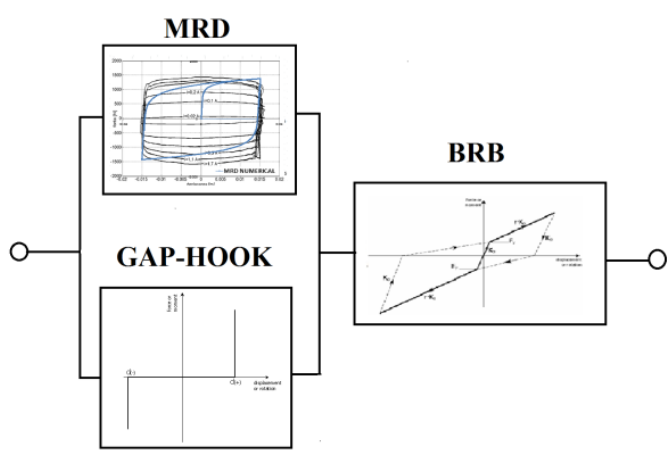

b.

Fig. 9 - a) Gap-hook link element[8]; b)Concept diagram for link element combination

A smooth transition during phases should be provided and as a result such a lock-out device must be carefully designed and calibrated. For the purpose of the current study the lock-out mechanism was introduced in the numerical model as a gap-hook link element (Fig. 9a)connected in parallel with the MRD damper (Fig. 9b) that engages at $\mathrm{d}=10 \mathrm{~mm}$ allowing for the transition between phases. The obtained behaviour is shown in Fig. 10.

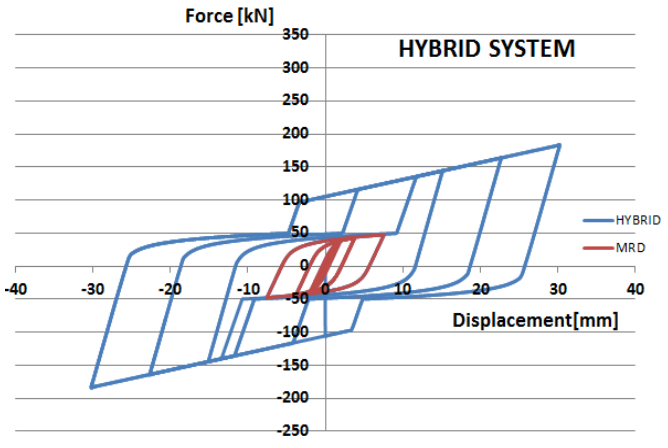

Fig. 10 - Hysteretic behaviour of hybrid MRD- BRB system.

The results for the hybrid system model show that the combined behaviour of the two passive devices follows the desired design concept. In the first stage the MRD is the active component providing energy dissipation at low levels of displacement, after which the lockout mechanism enables the transition to the second stage where the BRB is the active element. At this higher level of action the BRB will provide additional stiffness and energy dissipation.

In a performance based design approach this hybrid damper can be thought to provide energy dissipation through the MRD for levels of seismic action corresponding to immediate occupancy (IO) performance level. For higher level seismic actions corresponding to life safety (LS) and 
collapse prevention (CP) performance levels the hybrid system engages the BRB passive damper that will provide adequate level of energy dissipation (Fig. 11). This type of hybrid damper is useful in improving the behaviour of rigid structures that are sensitive to formation of plastic hinges at low levels of seismic action such as centrically braced structures. An improvement to the presented hybrid system would be the attachment of a control mechanism to the MRD enabling it as a semi-active device with the possibility to modify its behaviour, thus ensuring an optimal response for low level excitation. This could provide also the lockout mechanism of the system by increasing the stiffness in the damper in a way that can cause the yielding of the BRB brace.

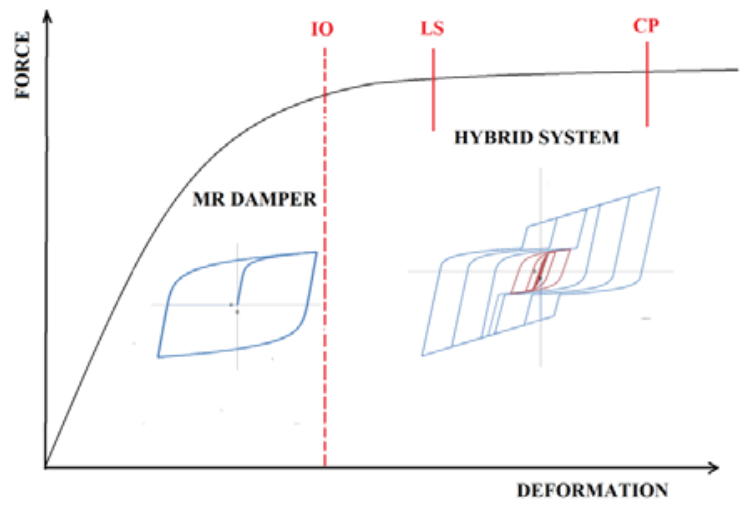

Fig. 10 - Conceptual use of hybrid MRD- BRB system.

\section{Conclusions}

A hybrid dissipative system developed from two damping devices is proposed and studied analytically. This hybrid system uses a MR fluid damper to provide damping and energy dissipation at low levels of seismic action and engages a BRB to provide energy dissipation at higher levels of seismic action. In a performance based design approach this hybrid damper can be thought to provide energy dissipation through the MRD for levels of seismic action corresponding to immediate occupancy (IO) performance level and through the BRB for higher level seismic actions corresponding to life safety (LS) and collapse prevention (CP) performance levels. In the current study the MR damper was considered to work as a passive device. A simple numerical model was developed to demonstrate the concept of multi-stage behaviour of the hybrid damper concept by connecting in series two numerical models calibrated on experimental data for the MR damper and for the BRB. In parallel with the MRD damper a lock-out mechanism was modelled by means of a gap-hook type element. This element engages the buckling of the BRB for set values of displacement making the phase transition between the two elements.

The paper summarise the first numerical trials for such a hybrid system in order to design an experimental testing program as part of on-going research program.

\section{Acknowledgements}

This work was supported by the strategic grant POSDRU/159/1.5/S/137070 (2014) of the Ministry of Labor, Family and Social Protection, Romania, co-financed by the European Social Fund - Investing in People, within the Sectorial Operational Program Human Resources Development 2007-2013. 


\section{References}

[1] Wenke, T. \& Eric, ML. (2014). Hybrid Recentering Energy Dissipative Device for Seismic Protection, Hindawi Publishing Corporation Journal of Structures, vol 2014, ID 262409.

[2] Amadio, C., Clamente, I., Macorini, L. \& Fragiacomo, M. (2008). Seismic behavior of hybrid systems made of PR composite frames coupled with dissipative bracings, Earthquake Engineering and Structural Dynamics, 37,861-879, Published online in Wiley InterScience DOI: 10.1002/eqe.790.

[3] Kim, D.H. (2013). Experimental Study on the Seismic Performance of Hybrid Buckling-Restrained Braces, Journal of Korean Society of Hazard Mitigation, Vol. 13, no. 4, 23-29, DOI: 10.9798/KOSHAM.2013.13.4.023.

[4] Filip-Vacarescu, N., Stratan, A.\& Dubina, D. (2014). Seismic Performance of Multistorey Steel Frames With Strain Hardening Friction Dampers - Part 1, Proceedings of the Romanian Academy, series A: Mathematics, Physics, Technical Sciences, Information Science,Vol. 1/2014, ISSN 1454-906.

[5] Panait, A., Serban,, V., Androne, M., Ciocan, G.A.\& Zamfir, M. (2007). Metoda ŞERB - SITON pentru controlul, limitarea si amortizarea miscarilor seismice a structureilor metalice, $A$ X-a editie a Zilelor academice timisene:Structuri metalice amplasate in zone seismice. Preocupari actuale..

[6] Filip-Vacarescu, N., Stratan, A.\& Dubina, D. (2014). Seismic Performance of Multistorey Steel Frames With Strain Hardening Friction Dampers - Part 1, Proceedings of the Romanian Academy, series A: Mathematics, Physics, Technical Sciences, Information Science,Vol. 2/2014, ISSN 1454-906.

[7] Tudor, S., Gheorghe, G. \& Danut, S. (2005). Magnetorheological fluids and dampers" (in Romanian), Bren Printing House, Bucuresti, ISBN 973-648-394-0.

[8] SeismoStruct v7.0 (2002) [computer software] - SEISMOSOFT, http://seismosoft.com.

[9] Clark, P., Aiken, I., Kasai, K., Ko, E.\& Kimura, I. (1999). Design Procedures for Buildings Incorporating Hysteretic Damping Devices, Proceedings 68th Annual Convention, Structural Engineers Association of California, Sacramento, CA, 1999, 355-371, Santa Barbara, California

[10]Bordea, S. (2010). Dual Frame Systems of Buckling Restrained Braces, PhD. Thesis, Universitatea POLITEHNICA din Timişoara Facultatea de Construcţii şi Arhitectură, Departamentul de Construcţii Metalice şi Mecanica Construcţiilor, ISBN 978-606-554-059-0.

[11]ECCS.1985 Recommended Testing Procedures for Assessing the Behaviour of Structural Elements under Cyclic Loads, European Convention for Constructional Steelwork, Technical Committee 1, TWG 1.3 - Seismic Design, No.45, 1985

[12] AISC, 2005, "Seismic Provisions for Structural Steel Buildings".American Institute of Steel Construction, Inc. Chicago, Illinois, USA. 